Supporting Information

\title{
Electrospray ionization inside the ion inlet tube: multi-jet mode operation
}

\author{
Zhongbao Han, Lee Chuin Chen*
}

Faculty of Engineering, University of Yamanashi, 4-3-11, Takeda, Kofu, Yamanashi, 400-8511 Japan

*To whom correspondence should be addressed:

L. C. Chen, E-mail: leechuin@yamanashi.ac.jp, Phone: +81-55-220-8072 


\section{Figure S1}
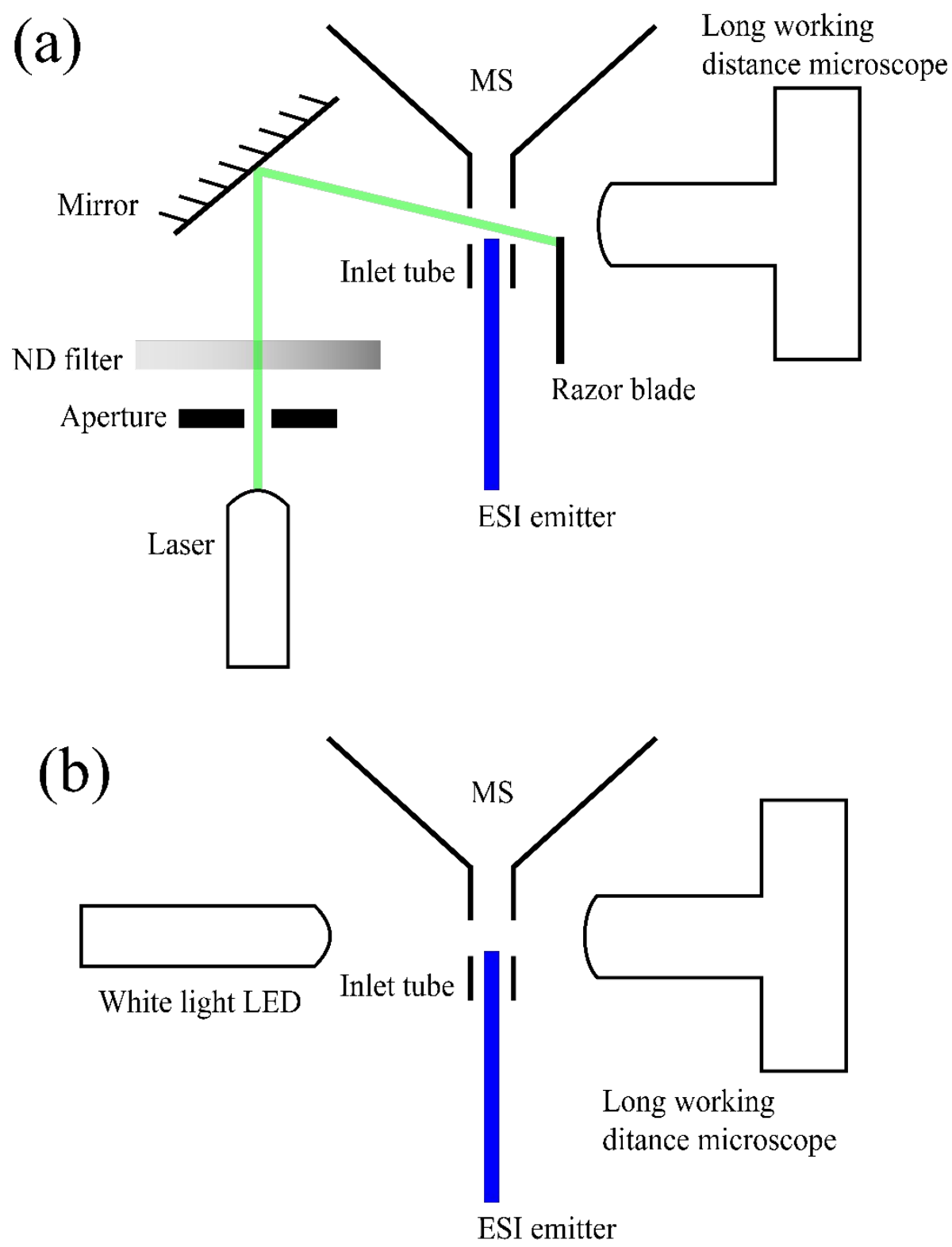

Schematics of the optical configuration for the visualization of the electrospray inside the ion inlet tube through the side holes. (a) Laser illumination. (b) White-light LED. ND: Neutral-density 


\section{Figure S2}

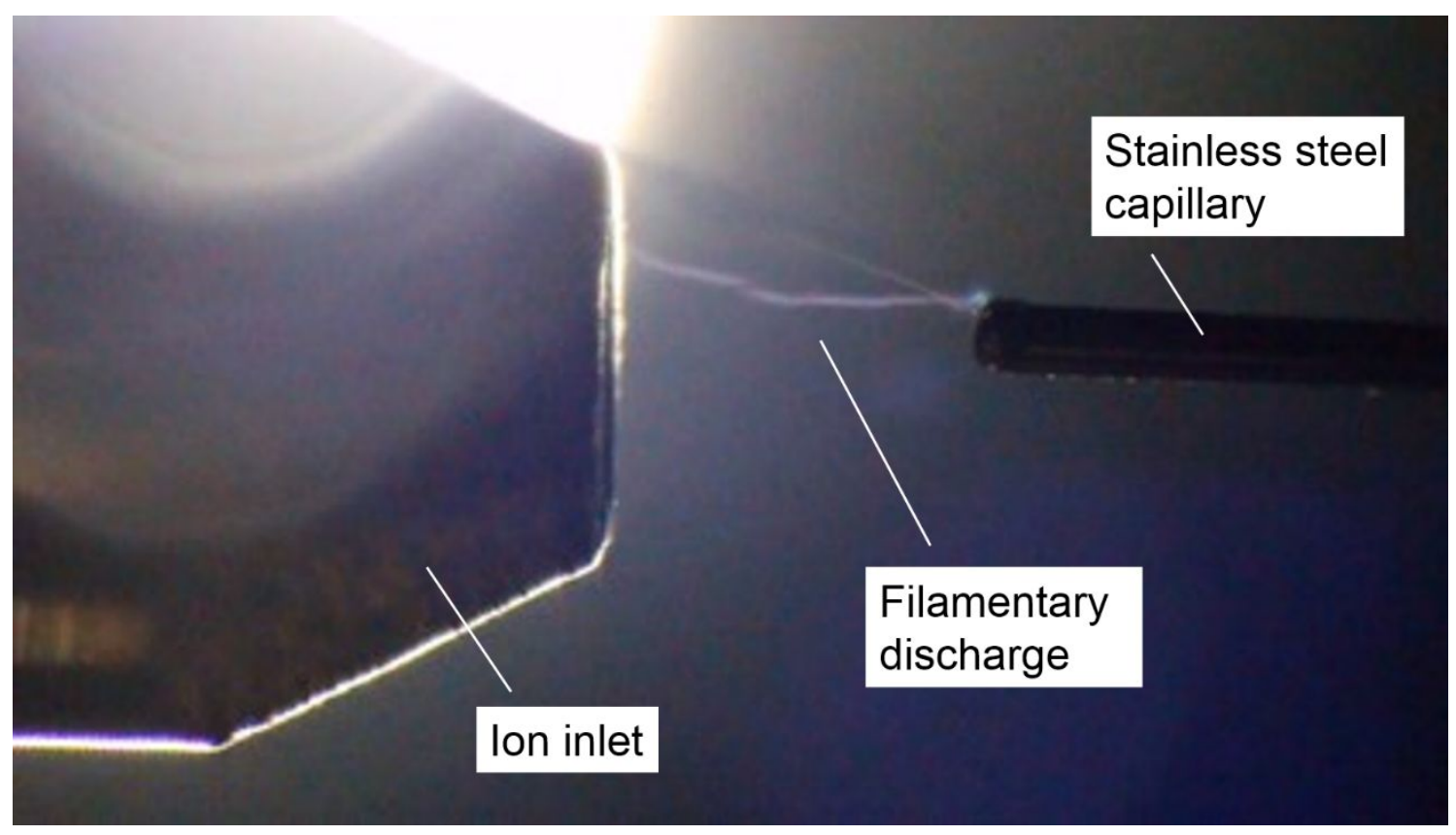

The occurring of filamentary discharge when the ESI capillary made of stainless steel is brought close to the ion inlet. The H.V. applied to the stainless-steel capillary is $1.5 \mathrm{kV}$. The distance between the capillary and the ion inlet is approximately $0.8 \mathrm{~mm}$. 


\section{Figure S3}
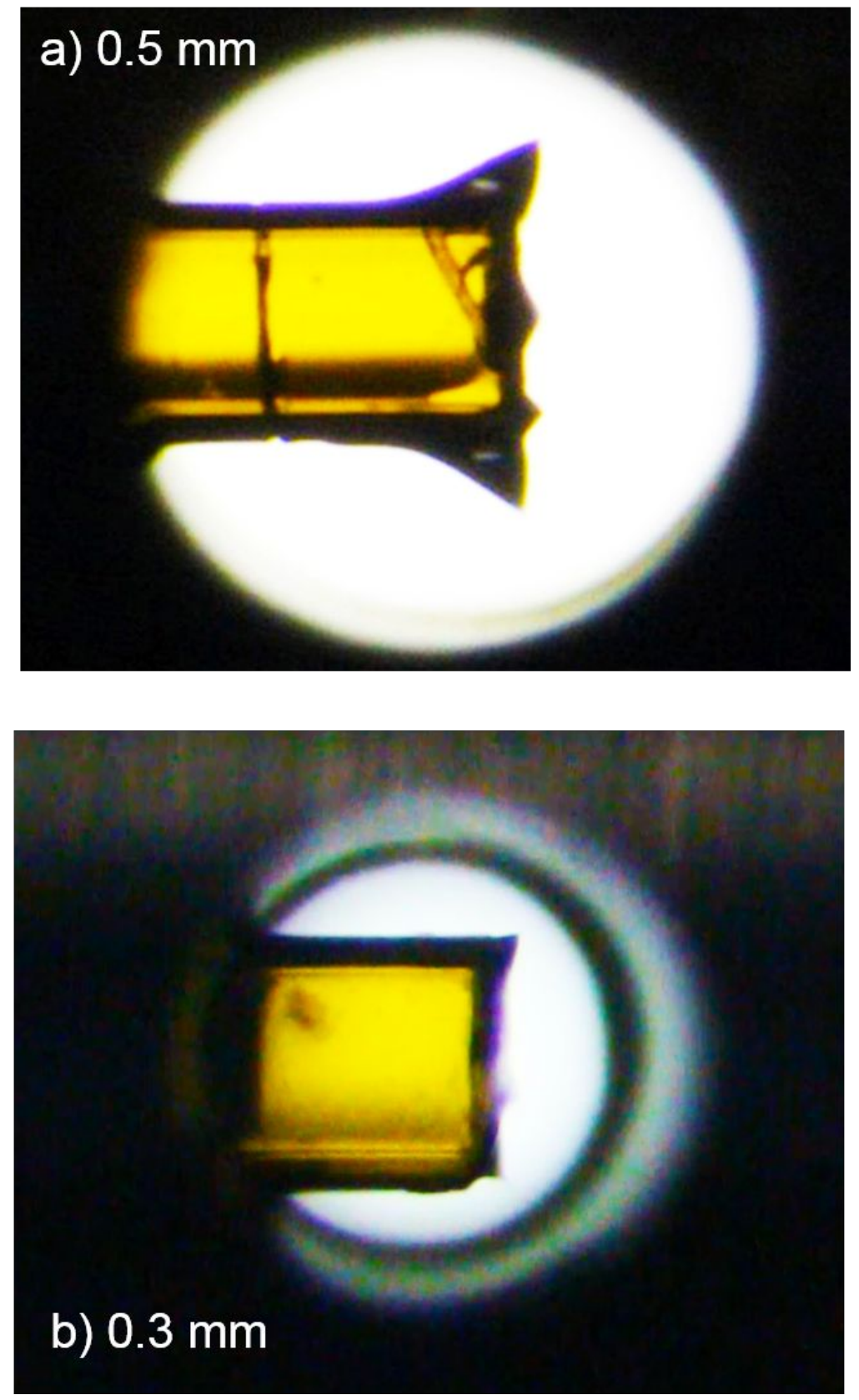

Observation of Taylor cone formed at the rim of the fused-silica capillary inside the ion inlet tube using side-holes of different sizes. a) Side holes diameter $=0.5 \mathrm{~mm}$. b) Side holes diameter $=0.3 \mathrm{~mm}$. 